75 cannabis (only) smokers, 91 cannabis and tobacco smokers and 92 tobacco smokers with 81 non-smokers. They found a dose-response relationship between cannabis consumption and the degree of airways obstruction and hyperinflation. They estimated that one cannabis joint was equivalent to 2.5 cigarettes for the effect on forced expiratory volume in $1 \mathrm{~s} /$ forced vital capacity and to 6 cigarettes for the effect on specific airways conductance. In contrast, there was no association between cannabis use and the prevalence of HRCT-defined emphysema. This study supports the view that cannabis affects airway function and causes obstruction. It is likely that the present results differ from the previous negative studies due to the inclusion of subjects with a relatively high cumulated cannabis consumption (substantial number of joint-years) and because the cannabis cigarettes of today contain more than 10 times as much THC than cigarettes from the 1960s, as has been put forward by the British Lung Foundation
(BLF). ${ }^{7}$ The BLF also points out that there is a need for further research focusing on the link between cannabis and chronic obstructive pulmonary disease. Yet, the study by Aldington et al also shows the difficulties in conducting such studies. ${ }^{6}$ In spite of the fact that the investigators invited a general population sample of 3500 individuals, there were only 19 eligible persons smoking cannabis. Another approach using specific advertising for cannabis smokers therefore had to be employed. However, as the authors point out, this approach is not without problems because many heavy cannabis consumers also smoke other substances, which makes it difficult to isolate the effects of cannabis.

In summary, although we know far less about the effect of cannabis on the lung than the effects of tobacco smoking, the study by Aldington et $a l^{6}$ confirms that cannabis smoking constitutes a substantial hazard to the lung.

Thorax 2007;62:1036-1037.

doi: $10.1136 /$ thx.2007.084830
Correspondence to: Dr Peter Lange, Department of Cardiology and Respiratory Medicine, Hvidovre Hospital, Copenhagen, Denmark; plange@dadlnet.dk

Competing interests: None.

\section{REFERENCES}

1 European Monitoring Centre for Drugs and Drug Addiction. Annual report on the UK drug situation in 2001. London: Drug Scope.

2 Johnson MR, Smith RP, Morrison D, et al. Large lung bullae in marijuana smokers. Thorax 2000;55:340-2.

3 Wu TC, Tashkin DP, Diahed B, et al. Pulmonary hazards of smoking marijuana as compared with tobacco. N Engl J Med 1988;318:347-51.

4 Tashkin DP. Smoked marijuana as cause of lung injury. Monaldi Arch Chest Dis 2005;63:93-100.

5 Tertrault JM, Crothers K, Moore BA, et al. Effects of marijuana smoking on pulmonary function and respiratory complications. Arch Intern Med 2007; 167:221-8.

6 Aldington S, Williams $M$, Nowitz M, et al. Effects of cannabis on pulmonary structure, function and symptoms. Thorax 2007;62:1058-63.

7 British Lung Foundation. A smoking gun? The impact of cannabis smoking on respiratory health. London: British Lung Foundation. www.lunguk.org/ smoking_gun.asp (accessed 8 October 2007).

\title{
Long-term exposures to air pollution
}

\section{Jon $\mathbf{G}$ Ayres}

\section{Methodological problems of retrospective studies}

I n the 1980s the comfortable belief that air pollution was no longer a public health issue was shaken by the appearance of the Six Cities study from the USA which revealed dose-related health effects (ranging from symptoms to mortality) at levels of air pollutants at that time considered to be safe. ${ }^{1}$ Since then there has been a dramatic rise in the number of publications on air pollution from all parts of the world which have resulted in two broad outcomes: a far better understanding of the mechanisms by which ostensibly "low" concentrations of pollutants impact on the lung and increasing awareness within governments of the need to tighten air quality standards. Most epidemiological studies over this time have considered the effects of day-to-day changes in air pollution on daily events such as deaths and hospital admissions (so-called time-series studies). ${ }^{2}$ While these studies are in theory easy to undertake, being based on routinely collected data, they usually lack individual information other than cause of death or admission, age and gender. Using this information, in 1998 the UK's Committee on Medical Effects of Air Pollutants (COMEAP) quantified the health impact of air pollution ${ }^{3}$ as a stepping stone towards determining the cost effectiveness of further pollution control measures. However, at that time they were unable to quantify the impact of long-term exposures-which even then were thought likely to be far greater than the day-to-day effects-for lack of studies.

Subsequently, the Six Cities studies ${ }^{4}$ and the much larger American Cancer Society (ACS) study of 151 US cities ${ }^{56}$ have provided insights into the effects of long-term exposure on mortality and, to some extent, morbidity. While these studies have been used by COMEAP in their second quantification report (the first section on mortality is now on the COMEAP website $^{7}$ ), there are no UK prospective longitudinal studies aimed at defining the effect of air pollution on health. Longitudinal studies from Norway and France $^{89}$ have shown associations between particles and mortality with coefficients ranging from 1.04 to 1.16 for a range of outcome and pollutant pairings, while a pilot study from the Netherlands ${ }^{10}$ has shown much larger effect sizes than the ACS study. The Dutch results might be due to small population size or be a real effect; the full study results are awaited with interest.

The paper by Elliott and colleagues in this issue of Thorax ${ }^{11}$ using a Geographical Information System-based small area approach should therefore be a welcome addition (see $p \mathbf{1 0 8 8}$ ). This is a retrospective ecological study of total mortality and thus has the inherent problems of such studies, but the findings are intriguing if true, the effect sizes being larger than those in the ACS study and comparable to the Dutch pilot study. Using black smoke as an index of particle exposure, the adjusted relative risks for respiratory mortality were $3.6 \%$ per $10 \mu \mathrm{g} / \mathrm{m}^{3}$ exposure to black smoke and $13.2 \%$ per $10 \mathrm{ppb}$ sulphur dioxide. Puzzlingly, for the most recent period from 1994-8 the coefficients were substantially higher at $19.3 \%$ and $21.7 \%$, respectively.

However, these findings need to be interpreted with some caution as timing of exposures, accuracy of estimated exposures and confounding may all be playing a part in inflating these effect sizes. This approach does consider past exposures as relevant to mortality, but only the few years immediately before the period of 
analysis are used which does not account for longer term exposures which will certainly be having an impact. A further issue is that of spatial autocorrelation, where the frequency or size of an exposure or outcome is dependent on adjacent geographical areas, a particular problem in these sorts of studies. ${ }^{12}$

One important issue in this study is that of confounding. The authors have adjusted to some extent for socioeconomic factors (important as, among other things, poorer individuals are more likely to live on main roads) using the Carstairs index, but the structure of this index varies geographically and over time. While this might to some extent allow for smoking, the lack of individual smoking data is also a source of confounding. In addition, this is not helped by the spatial change in the population studied over time and, even though the study looked at over 420000 deaths, this variation will be a source of bias. In addition, the population is not truly representative of the total UK population as the wards studied were more urban and more deprived than the average UK ward.

There are two other aspects which are difficult to explain: the findings of a larger effect size for sulphur dioxide than black smoke and the larger effect size when considering more recent exposures. Sulphur dioxide keeps providing positive associations with health end points, especially in European studies, but levels in the UK have fallen and matching the mechanisms to any effect of this gas at these low levels is a problem. Why are there apparently greater effects when considering exposure during recent years when levels have continued to fall? If not artefactual (as the authors discuss), it could be explained on the basis that relative rather than absolute increases in a pollutant level day-to-day is the driver of a health impact. Studying the relative (or absolute) change in level (eg, from the previous day) would give insight into this possibility. The mechanistic discussion in this paper was limited to the formation of sulphate as a potential pathway without considering how sulphate itself might be toxic. Sulphate is a non-toxic ion but, while it is conceivable that it acquires an element of toxicity when formed as a salt such as iron or ammonium sulphate, short-term human exposure studies to higher than ambient doses of a range of sulphates $^{13}$ have been negative. While a biological explanation is not necessary when attributing a causal impact to an exposure, where the biology seems to point away from a logical explanation, consideration has to be given to alternative explanations which may well in this case be methodological.

If the full Netherlands study produces effect sizes comparable to the pilot, then this might lend support to the effect sizes reported by Elliott et $a l^{11}$ but, if the Dutch findings are more akin to those in the ACS study, then the methodology of retrospective studies with difficulties in confounding and exposure inaccuracies may be the explanation for the high effect sizes reported here. In the latter case, how then might the question of the effect of long-term exposure to current air pollution be assessed? Consideration could be given to a longitudinal European study which would also address other environmental factors (such as diet and indoor air pollution) on health. Such a prospective study would deal with the problems that beset the use of retrospective datasets, could address gene environment interactions and would provide definitive quantification of the effects of long-term exposure to air pollution. The study would be very ambitious and expensive and results, by definition, would be slow in coming, but the only option otherwise is to continue to use US coefficients in our assessments or information from retrospective studies from Europe. At present the results using these two options would be disparate-and which would you choose to use?
Thorax 2007;62:1037-1038.

doi: $10.1136 /$ thx.2007.080101

Correspondence to: Professor Jon G Ayres, Department of Environmental and Occupational Medicine, University of Aberdeen, Foresterhill Road, Aberdeen AB25 2ZP, UK; i.g.ayres@ abdn.ac.uk

Competing interests: None.

\section{REFERENCES}

1 Dockery DW, Pope CA III, Xu X, et al. An association between air pollution and mortality in six US cities. N Engl J Med 1993;329:1753-9.

2 Bell ML, Samet JM, Dominici F. Time-series studies of particulate matter. Ann Rev Pub Health 2004;25:247-80.

3 Department of Health. Committee on the Medical Effects of Air Pollutants. Quantification of the effects of air pollution on health in the United Kingdom. London: The Stationery Office, 1998. http:// www.advisorybodies.doh.gov.uk/comeap/ statementsreports/airpol7.htm (accessed 26 September 2007).

4 Laden F, Schwartz J, Speizer FE, et al. Reduction in fine particulate air pollution and mortality: extended follow-up of the Harvard Six Cities study. Am J Respir Crit Care Med 2006;173:667-72.

5 Pope CA III, Thun MJ, Namboodiri MM, et al. Particulate air pollution as a predictor of mortality in a prospective study of US adults. Am J Respir Crit Care Med 1995; 151:669-74.

6 Pope CA III, Burnett RT, Thun MJ, et al. Lung cancer, cardiopulmonary mortality and long-term exposure to fine particulate air pollution. JAMA 2002;287: 1132-41.

7 Department of Health. Committee on the Medical Effects of Air Pollutants (COMEAP). London: Department of Health, updated 2007, http:// www.advisorybodies.doh.gov.uk/comeap (accessed 26 September 2007).

8 Nafstad P, Haheim LL, Wisloff T, et al. Urban air pollution and mortality in a cohort of Norwegian men. Environ Health Perspect 2004; 1 12:610-5.

9 Filleul L, Rondeau V, Vandentorren S, et al. Twenty five year mortality and air pollution: results from the French PAARC survey. Occ Environ Med 2005;62:453-60.

10 Hoek G, Brunekreef B, Goldbohm S, et al. Association between mortality and indicators of traffic-related air pollution in the Netherlands: a cohort study. Lancet 2002;360:1203-9.

11 Elliott P, Shaddick G, Wakefield JC, et al. Longterm associations of outdoor air pollution with mortality in Great Britain. Thorax 2007:62:1088-94.

12 Jerrett M, Burnett RT, Ma R, et al. Spatial analysis of air pollution and mortality in Los Angeles. Epidemiology 2005;16:726-36.

13 Tunnicliffe WS, Kelly FJ, Dempster C, et al. The effect of sulphurous air pollutant exposures on symptoms, lung function, exhaled nitric oxide and nasal epithelial lining fluid antioxidant concentrations in normal and asthmatic adults. Occup Environ Med 2003;60:e15. 